\title{
C Research Square \\ Hydrothermal-alkaline conversion of sewage sludge: Focus on optimization of process parameters and characterization of humic acid
}

\section{Chen Qiu}

SCUT: South China University of Technology

\section{Wenbing Xu}

Dongjiang Environmental Company Limited, Shenzhen, Guangdong

\section{Yanjie Wang}

Dongjiang Environmental Company Limited, Shenzhen, Guangdong

Jiakuan Yang

HUST: Huazhong University of Science and Technology

Xintai Su ( $\nabla$ suxintai827@163.com )

SCUT: South China University of Technology https://orcid.org/0000-0001-6615-5273

Zhang Lin

SCUT: South China University of Technology

\section{Research Article}

Keywords: Sewage sludge, Dewatering, Humic acid, Recycling, Hydrothermal treatment, Response surface methodology

Posted Date: March 9th, 2021

DOl: https://doi.org/10.21203/rs.3.rs-221496/v1

License: (c) (1) This work is licensed under a Creative Commons Attribution 4.0 International License. Read Full License 


\section{Abstract}

Sewage sludge (SS) dewatering is a key step in sludge disposal, which plays an important role in reducing sludge volume, facilitating transportation and subsequent treatment. In recent years, many studies have focused on sludge hydrothermal dewatering, while resource recovery during this process is less studied, especially humic substances. In this paper, a facile and low-cost hydrothermal-alkaline treatment for SS was proposed, which can be used for sludge dewatering and humic acid (HA) recycling at the same time. Response surface methodology (RSM) was used to determine the optimal conditions, and a mathematical model was established to accurately predict the change of sludge water content and the extraction rate of HA. Under the optimal conditions of $170^{\circ} \mathrm{C} / 42 \mathrm{~min} / 0.05$ (for hydrothermal temperature, hydrothermal time and mass ratio of $\mathrm{KOH}$ to wet sludge, respectively), the water content decreased to $46.7 \%$ and the extraction rate of HA (with a purity of $96.2 \%$ ) was $89.1 \%$. The improvement of the dewatering performance effectively facilitates the subsequent disposal of the sludge. The extraction of HA not only solves the problem that the sludge separation liquid needs further treatment, but also has potential economic value in agriculture, biological medicine, environment and other fields.

\section{Introduction}

Sewage sludge (SS) is the main by-product of sewage treatment plant. With the rapid development of industrialization and urbanization, about $400 \sim 600$ million-ton sludge (water content of $80 \%$ ) can be produced from wastewater treatment plants in China each year (García et al., 2017). The cost of sludge treatment and disposal accounts for about $50 \% \sim 65 \%$ of the total operation cost of sewage treatment plants (Zhao et al., 2016; Appels et al., 2008). The sludge is rich in water, heavy metals and a small number of pathogenic microorganisms, parasitic eggs and other harmful substances (Zhang et al., 2018; Lu et al., 2020). Sludge without proper treatment may become a secondary source of pollution and enter the food chain through the atmosphere, groundwater, surface water and soil. It seriously endangers human health and causes ecological risks. Therefore, the disposal of SS has become an increasingly important problem.

Dewatering is the key step of sludge treatment, which can minimize the sludge volume, facilitate the transportation. The reduction of sludge volume is also closely related to the economic feasibility of subsequent treatment and disposal such as landfill and incineration (Wu et al., 2020). In order to improve the dewatering capacity of sludge and achieve the effect of deep dewatering, a variety of dewatering processes have been widely studied and developed. Chen et al. (2020) enhanced the hydrolysis of polysaccharides and proteins by acidification and the water content of sludge cake was reduced to $60 \%$ under the optimum condition. Kim et al. (2020) enhanced the dewaterability by thermal hydrolysis pretreatment and reduced the water content to $55.38 \%$. Li et al. (2017) studied the combination of thermal hydrolysis and alkalization and achieved excellent dehydration effect (31\%). The principle of these technologies is to promote the release of bound water, intracellular water and extracellular polymeric substances (EPS) into the water phase. However, the destruction of sludge cells and the release of organic matter increase the concentration of biochemical oxygen demand (BOD) and chemical oxygen 
demand (COD) in the sludge separation liquid, which not only increases the burden of subsequent processing, but also causes waste of resources (Neyens and Baeyens, 2003a, 2003b; Zhang et al., 2019). Hence, it is essential to realize resource recovery in the sludge dewatering process.

The resource utilization of sludge is mainly aimed at the rich organic matter (Protein, chitosan and humus et al.) and nutrients (nitrogen, phosphorus and potassium). Many approaches have been studied to facilitate the utilization of sludge. Such as energy recovery technology through combustion to recover heat, through thermal decomposition and anaerobic digestion technology to recover biomass (MarinBatista et al., 2020; Wang et al., 2019; Wang et al., Dewil et al., 2007). Resource recovery technology through pyrolysis to prepare biochar as adsorbent or soil conditioner (Figueiredo et al., 2019; Zhou et al., 2018; Jin et al., 2016), extract humic acid (HA), nitrogen, phosphorus, potassium and other nutrients as fertilizer (Li et al., 2009; Anielak et al., 2018; Quist-Jensen et al., 2018; Kulikowska et al., 2020). However, sludge dewatering and recycling are usually carried out separately at present, resulting in complex operation and high treatment cost. The development of new sludge dehydration and resource utilization synergistic technology is the inevitable requirement and development trend in the future.

Humus is the main component of sludge organic matter, accounting for about 35\% (Li et al., 2014), which can be used as raw material for extracting HA organic fertilizer. The process of HA resource recovery in the sludge dewatering process is less reported. In this study, a simple, low-cost method for sludge dewatering and HA extraction was proposed. hydrothermal-alkali treatment was used to destroy the sludge flocs and cells to release the organic pollutants, and then HA was extracted from the decomposition liquid by using the characteristics of alkali dissolution and acid precipitation (Gu et al., 2019; Liu et al., 2019). Through single factor and response surface optimization (RSM) experiments, the optimal conditions were determined, and the mathematical models for accurately predicting the change of sludge water content and the extraction rate of HA were established. It provides a reference for sludge reduction and resource utilization.

\section{Materials And Methods}

\subsection{Raw sludge and chemicals}

The raw sludge (RS) used in this study was obtained from a domestic sewage treatment plant located in Guangzhou, Guangdong Province, China. The collected sludge was stored at $4{ }^{\circ} \mathrm{C}$ before use. The main characteristics of RS sample are shown in Table 1. The reagents such as potassium hydroxide $(\mathrm{KOH})$, hydrochloric acid $(\mathrm{HCl})$, sulfuric acid $\left(\mathrm{H}_{2} \mathrm{SO}_{4}\right)$ were of analytical grade and purchased from Shanghai Aladdin Bio-Chem Technology Corporation Ltd.

\subsection{Process for sludge dewatering and HA extraction}

Batch experiments of sludge dewatering and HA extraction were carried out in a hydrothermal reactor. Mixing $30 \mathrm{~g}$ of sludge with a certain amount of alkali, and putting the mixture into an oven for hydrothermal reaction. Centrifuging $(5000 \mathrm{r} / \mathrm{min}, 5 \mathrm{~min})$ the reacted solution to obtain dewatered sludge 
and solution containing HA. The water content of the sludge is measured by a moisture tester (Text S1), and the HA is extracted and purified by utilizing the characteristics that the HA is dissolved under an alkaline condition and precipitated under an acidic condition (Li et al., 2014; Cristina et al., 2020).

\subsubsection{Single factor test}

In order to investigate the effects of various factors on sludge dewatering and HA extraction, single factor experiments were carried out with hydrothermal temperature $\left(150,160,170,180,190,200^{\circ} \mathrm{C}\right)$, hydrothermal time $(30,60,90,120,150,180 \mathrm{~min})$ and alkali sludge ratio $(\mathrm{g} \mathrm{KOH}: \mathrm{g}$ wet sludge $)(0: 1$, $0.01: 1,0.02: 1,0.04: 1,0.08: 1,0.16: 1)$ as factors.

\subsubsection{Response surface design}

The above single factor experiments cannot consider the interaction of all factors, and also requires a large number of experiments (Uma Maheswar Rao and Satyanarayana, 2007). RSM is an effective statistical method for the study of complex variable processes. This method can effectively describe the interaction between independent experimental factors and response values (Yang et al., 2011; Ghafarzadeh et al., 2017). Therefore, on the basis of single factor method, RSM was used to determine the optimal reaction parameters of sludge hydrothermal-alkali dehydration and HA extraction. Taking the water content after extracting $\mathrm{HA}$ and the extraction rate of $\mathrm{HA}$ as response variables and hydrothermal temperature $\left(X_{1}\right)$, hydrothermal time $\left(X_{2}\right)$ and alkali-sludge ratio $\left(X_{3}\right)$ as response factors, 17 groups of experiment with three factors and three levels were designed to analyze the interaction of various factors on the response value, to determine the functional relationship between the response value and the influencing factors.

\subsection{Calculation of extraction rate of $\mathrm{HA}$}

The extraction rate of HA in this experiment refers to the mass of sludge HA extracted from unit mass of dry sludge, which is expressed by $W$, and the following Eq. (1) describes the calculation method of the extraction rate of $\mathrm{HA}$ :

\section{see formula 1 in the supplementary files.}

In the formula, $m$ is the mass of the extracted HA (g), $\omega$ is the content of HA in unit mass of dry sludge (\%), $p$ is the water content of sludge (\%), and the determination method of $\omega$ is shown in the supporting materials (Text S2.).

\subsection{Characterization of $\mathrm{HA}$}

A batch of HA was extracted under the optimal conditions, and the carbon content of HA was determined by volumetric method according to Standard GB/T 23349-2009, and then the mass fraction of the HA was calculated according to the carbon content coefficient of the biochemical HA. Modern instrumental analyses such as inductively coupled plasma atomic optical emission spectrometer (ICP-OES), Fourier 
transform infrared spectroscopy (FTIR), Scanning electron microscopy (SEM) and Gel Permeation Chromatography (GPC) have been applied in the characterization of the compositions of HA. An ICP-OES (Perkin Elmer, Avio ${ }^{\text {TM }} 200$, CA, USA) was used to determine the concentration of heavy metal in obtained HA. The FTIR spectra of the HA were measured with a FTIR spectrometer (NICOLET 8700, Thermo Fisher Scientific, USA). SEM (Philips XL30 electron microscope, Holland) was applied to observe the morphology of the HA. The average values of molecular weights and the molecular-weight distribution of HA was measured by GPC (Water 1525 \& Agilent PL-GPC2200).

\section{Results And Discussion}

\subsection{Analysis of single factor test results}

The effect of hydrothermal temperature, hydrothermal time and ratio of $\mathrm{KOH}$ to sludge on water content are shown in Fig. 1 (a), (b) and (c). And the effect of these factors on HA extraction rate are shown in Fig. 1 (d), (e) and (f). The results of the single factor tests indicate that the improvement of sludge dewatering performance is consistent with the increase of HA extraction rate. The best effect is achieved under the same single condition, which proves that it is possible to achieve dehydration and HA extraction in the same process. In Fig. 1(a) and (d), the effect of temperature on improving the dehydration performance and $\mathrm{HA}$ extraction rate show a trend of first promotion and then inhibition, and the best effect at $180{ }^{\circ} \mathrm{C}$. From Fig. 1(b) the water content of sludge decreases rapidly in $0 \sim 30$ min, and slowly in $30 \sim 60$ min. The water content of sludge reach equilibrium in $60 \mathrm{~min}$, and the lowest water content is $47.96 \%$. It can be seen from Fig. 1(e) that within 60 min, the extraction rate of HA increases with the increase of hydrothermal time, and the maximum extraction rate reaches $82.2 \%$ at $180^{\circ} \mathrm{C}$. The effect of alkali dosage in Fig. $1(\mathrm{c})$ and (f) show that with the increase of $\mathrm{KOH}$ dosage, the dehydration performance increased first and then decreased, the HA extraction increased first and then decreased. The optimal effect both achieve when the ratio of alkali to sludge was 0.04 .

\subsection{Statistical analysis}

\subsubsection{Optimization of operating variables and analysis of their interaction}

In order to study the optimal process parameters of sludge dewatering and HA extraction, 17 groups of experiment designed by Box-Behnken. The results at each point based on the experiment design for the change of water content and HA extraction rate are shown in Table 2. And the response surface experimental scheme data (Table 2) designed by Box-Behnken were fitted. Quadratic polynomial equations for responses using relative parameters were established as described below in Eq. (2) and (3): see formulas 2 and 3 in the supplementary files.

In the above quadratic equation, $Y_{1}$ is water content of the sludge, $Y_{2}$ is extraction rate of $H A, X_{1}$ is the hydrothermal temperature, $X_{2}$ is the hydrothermal time and $X_{3}$ is the ratio of alkali to sludge. 
The significance and universal applicability of the quadratic model can be checked by variance (ANOVA) of experimental data, as shown in Table S1 and Table S2 in supplemental material. The square statistics $\left(R^{2}\right)$ of Eq. (2) and (3) were 0.9890 and 0.9915 , respectively, indicating that the model fitted the response well, and only $1.1 \%$ and $0.85 \%$ of the total variations could not be explained by the model Eq. (2) and (3) respectively. According to the analysis of variance, the P-value and F-value determined the significance of each term at the designed level of confidence. P-value below 0.05 indicates that the factor has a significant effect on the response values (Ooi et al., 2018). The P values of Eq. (2) and (3) were all less than 0.0001. The F-values of Eq. (2) and (3) were 69.91 and 90.19, respectively, which were much higher than the standard $F$ value $\left(F_{0.05}=4.25\right)$. The residual analysis diagrams (Fig. S1, Fig. S2) of the two models also show that all kinds of errors are within the normal range, indicating the accuracy of the model data Therefore, the two models are highly significant and adequate to describe the response.

\subsubsection{RSM analysis}

The interactions between the model terms were expressed by a three-dimensional surface plot. While plotting the surface between two of the independent variables and the response value, keep the other independent variables at their respective zero level (Yang et al., 2011). A high F-value and a low P-value indicate significance in the model equation (Mazaheri et al., 2010). ANOVA analysis shown in Table S1 indicate that the change of sludge water content $\left(Y_{1}\right)$ was significantly dependent on the independent variables $X_{2}, X_{3}$ and the quadratic term $X_{1}{ }^{2}$. The three-dimensional plots Fig. 2 (a) $\sim$ (c) reveal that the water content of sludge decreased slowly with the increase of hydrothermal time, and decreased first and then increased with the increase of hydrothermal temperature. The ratio of alkali to sludge had the most significant effect on the change of water content of sludge, and the water content decreased rapidly with increase of alkali dosage. The change of water content can be attributed to the destruction of cell structure by heat treatment, which leads to the dissolution of sludge organic matter and the release of bound water and improves the dewaterability. Meanwhile, the destruction of cell structure reduces the particle size of sludge, which is not conducive to dewaterability. Therefore, the effect of heat treatment on sludge dewaterability reaches a balance under a certain condition. The experiment on municipal sludge showed that the hydrolysis rate was the highest at $165-180{ }^{\circ} \mathrm{C}$, and the contact time (10 $\left.30 \mathrm{~min}\right)$ had little effect on the hydrolysis rate (Schnell et al., 2020; Wang et al., 2020). Fig. 2(d) is a comparison graph of the predicted value of the model and the change of the actual sludge water content. It can be seen from the figure that the experimental values and predicted values are distributed around a straight line, indicating that the model fits well.

ANOVA analysis shown in Table $S 2$ show that the HA extraction rate $\left(Y_{2}\right)$ was significantly dependent on the independent variables $X_{1}, X_{2}, X_{3}$, the quadratic term $X_{3}^{2}$ and the interaction term $X_{1} X_{3} . X_{3}$ and $X_{3}{ }^{2}$ have the largest $F$-value, which shows that the ratio of alkali to sludge is the most important factor affecting the extraction rate of HA. Fig. 3(a) (c) show that the extraction rate of HA increases slowly with the increase of temperature, decreases with the increase of time, and increases rapidly with the increasing of alkali sludge ratio. Fig. 2(d) shows the comparison between the predicted value of the 
model and the actual extraction rate of HA, and the linear correlation is very high, which shows that the model has accurate judgment and good fitting degree for the actual process.

\subsection{Analysis and validation of response surface optimization condition}

In order to optimize the process parameters of simultaneous extraction of HA from hydrothermally dehydrated sludge, the factors were limited in the experimental range, the response value of sludge water content target was set to be the lowest, and the HA extraction rate target was set to be the highest. The optimal solution is that the hydrothermal temperature is $169.42^{\circ} \mathrm{C}$ (taken as $170{ }^{\circ} \mathrm{C}$ ), the hydrothermal time is $41.99 \mathrm{~min}$ (taken as $42 \mathrm{~min}$ ), and the ratio of alkali to sludge is 0.05 . Under these conditions, the predicted value of sludge water content is $47.2 \%$, and the predicted value of HA extraction rate is $91.0 \%$.

To verify the effectiveness of the optimal parameters, validation tests were carried out. The water content was $46.7 \%$ and the extraction rate of HA was $89.1 \%$ under the optimal condition. The results were very close to the predicted values, which indicated that the two models fitted well and could be used to predict the change of sludge water content and the extraction rate of HA in the process of sludge dewatering and HA extraction. The improvement of sludge dewatering performance is better than that reported in the literature (Table S3). The determination method of HA purity is the same as the method of the content of HA in unit mass of dry sludge (Text S2). And the purity of the HA product is $96.2 \%$.

\subsection{Analysis on the properties of $\mathrm{HA}$}

\subsubsection{Heavy metal analysis}

Heavy metals are dangerous chemicals and toxic substances which should be limited within national standard when using for agriculture, biomedicine applications. ICP-OES analysis of samples was performed to evaluate the content of heavy metal of HA. The mass fraction of heavy metals in the purified HA in the study and its comparison with the values in National Standard GB/T 23349-2009 are shown in Table 3. The concentrations of heavy metals detected in HA are in permissible levels and are safe from the toxicological view for health.

\subsubsection{FTIR analysis of HA}

The FTIR spectra of the HA extracted from the sludge is shown in Fig. 4. The interpretation is based on the work of Sarlaki et al. (2019), Nasir et al. (2011) and He et al. (2008). The absorption bands in 3400 $\mathrm{cm}^{-1}$ are due to stretching vibrations of $-\mathrm{OH}$ or $-\mathrm{NH}$ groups with varying degrees of hydrogen bonding. The absorption peaks of $2928 \mathrm{~cm}^{-1}$ and $2850 \mathrm{~cm}^{-1}$ are aliphatic $-\mathrm{CH}_{3}$ deformation vibration and $-\mathrm{C}-\mathrm{H}$ extension vibration. The absorption bands in $1650 \mathrm{~cm}^{-1}$ was an amide I band or a peptide bond vibration and $1540 \mathrm{~cm}^{-1}$ was an amide $\Pi$ band or an absorption peak of heterocyclic $\mathrm{N}$ vibration. The absorption bands in $1450-1465 \mathrm{~cm}^{-1}$ region was assigned to the $\mathrm{C}=\mathrm{C}$ stretching in aromatic compounds, the stretching of aliphatic $-\mathrm{CH}_{2},-\mathrm{CH}_{3}$ and $-\mathrm{NH}_{2}$ vibration in peptide. The spectrum also showed bands at 1380 $\mathrm{cm}^{-1}$ (-C-H deformation of $-\mathrm{CH}_{2}$ and $-\mathrm{CH}_{3}$ salts of carboxylic acid) and $1200-1260 \mathrm{~cm}^{-1}$ (C=O stretching 
vibration of esters, ethers and phenols). The band at $1040 \mathrm{~cm}^{-1}$ is attributed to $\mathrm{R}-\mathrm{OH}$ or $-\mathrm{SO}_{3}$ vibration. The results of infrared spectrum show that HA contains a large number of phenolic hydroxyl, alcoholic hydroxyl, nitro, aromatic and aliphatic compounds, and more peptide bonds, ether bonds, amide and other functional groups than mineral HA.

\subsubsection{SEM analysis of HA}

The HA microscopic images are shown in Fig. 5. Fig. 5(a) is a microscopic image of HA magnified 500 times. It was observed that the shape and size of HA are not regular and uniform. The particle size distribution of the HA is between 10 and $30 \mu \mathrm{m}$. In higher magnifications (2500 times in Fig. 5(b) and Fig. 5(c), and 10000 times in Fig. 5(d)), surfaces with a smooth, non-porous and sponge-like appearance are observed in HA, its loose structure is similar to the HA extracted and purified from lignite waste by Nasir et al. (2011).

\subsubsection{Analysis of GPC}

The relative molecular mass and its distribution of the HA were measured by GPC, and the results are shown in Fig. 6. According to the principle of gel chromatography, the peaks of the compounds appear in turn according to the molecular weight. It can be seen from Table 4 that the number-average molecular weight $\left(M_{n}\right)$ and weight-average molecular weight $\left(M_{W}\right)$ of HA are 20602 and 43015 respectively, which are smaller than the molecular weight of commercial HA reported in literature (148616) (Janoš and Tokarová, 2002) and larger than HA extracted from peat (33700) (Novak et al., 2001). Polydispersity (PDI, $M_{W} / M_{n}$ ) can be used to indicate the molecular weight distribution of a substance. If the PDI value is close to 1 , it indicates that the molecular weight distribution of the substance is narrow. If the PDI value is $\geq 2$, it indicates that the molecular weight distribution of the substance is broad (Cheng et al., 2018). The PDI value of HA extracted from sludge in this paper was 2.0879, which indicated that the molecular weight distribution of HA was wide.

\section{Conclusion}

In this paper, the deep dehydration of sludge and the extraction of HA were realized simultaneously by hydrothermal-alkali treatment. RSM was adopted to estimate the effect of the three key factors on process of sludge reduction and reclamation and to optimize the process parameters. According to experiments and statistical analysis, the water content was $46.7 \%$ and the extraction rate of HA was $89.1 \%$ under the optimal conditions, which closely matched the predicted value. The low water content of sludge fully meets the requirements of subsequent disposal. HA with rich functional groups, high purity and safety has potential economic values.

\section{References}


Anielak et al., 2018. A.A.A.M. Anielak, M.K.M. Krylow, D.L.D. Lominska-Platek. Characterization of fulvic acids contained in municipal sewage purified with activated sludge. Arch. Environ. Prot., 44 (1) (2018), pp. $70-76$

Appels et al., 2008. L. Appels, J. Baeyens, J. Degrèveet, R. Dewil. Principles and potential of the anaerobic digestion of waste-activated sludge Prog. Energy Combust., 34 (2008), pp. 755-781

Chen et al., (2020). N. Chen, S. Tao, K. Xiao, S. Liang, J. Yang, L. Zhang. A one-step acidification strategy for sewage sludge dewatering with oxalic acid. Chemosphere, 238 (2020), p. 124598

Cheng et al., 2018. X. Cheng, H. Zhang, J. Hu, L. Feng, X. Gu, C. Jean-Pierre. Characterization of broad molecular weight distribution polyethylene with multi-detection gel permeation chromatography. Polym. Test, 67 (2018), pp. 213-217

Cristina et al., 2020. G. Cristina, E. Camelin, C. Ottone, S.F. Garofalo, L. Jorquera, M. Castro, D. Fino, M.C. Schiappacasse, T. Tommasi. Recovery of humic acids from anaerobic sewage sludge: Extraction, characterization and encapsulation in alginate beads. Int. J. Biol. Macromol., 164 (2020), PP. 277-285

Dewil et al., 2007. R. Dewil, J. Baeyens, L. Appels. Enhancing the use of waste activated sludge as bio-fuel through selectively reducing its heavy metal content. J. Hazard. Mater., 144 (3) (2007), pp. 703-707

Figueiredo et al., 2019. C.C.D. Figueiredo, J.K.M. Chagas, J.D. Silva, J. Paz-Ferreiro. Short-term effects of a sewage sludge biochar amendment on total and available heavy metal content of a tropical soil. Geoderma, 344 (2019), pp. 31-39

García et al., 2017. M. García, J. L. Urrea, S. Collado, P. Oulego, M. Díaz. Protein recovery from solubilized sludge by hydrothermal treatments. Waste Manag., 67 (2017), pp. 278-287

Ghafarzadeh et al., 2017. M. Ghafarzadeh, R. Abedini, R. Rajabi. Optimization of ultrasonic waves application in municipal wastewater sludge treatment using response surface method. J. Clean. Prod., 150 (2017), pp. 361-370

Gu et al., 2019. N. Gu, J. Liu, J. Ye, N. Chang, Y. Liu. Bioenergy, ammonia and humic substances recovery from municipal solid waste leachate: A review and process integration. Bioresour. Technol., 293 (2019), p. 122159

He et al., 2008. M. He, Y. Shi, C. Lin. Characterization of humic acids extracted from the sediments of the various rivers and lakes in China. J. Environ. Sci. (China), 20 (11) (2008), pp. 1294-1299

Janoš and Tokarová, 2002. P. Janoš, V. Tokarová. Characterization of coal-derived humic substances with the aid of low-pressure gel permeation chromatography. Fuel, 81 (8) (2002), pp. 1025-1031

Jin et al., 2016. J. Jin, Y. Li, J. Zhang, M. Wong, M. Wang, S. Shan, P. Christie. Influence of pyrolysis temperature on properties and environmental safety of heavy metals in biochars derived from municipal 
sewage sludge. J. Hazard. Mater., 320 (2016), pp. 417-426

Kim et al., 2020. H. Kim, K. Chon, Y. Lee, Y. Kim, A. Jang. Enhanced mechanical deep dewatering of dewatered sludge by a thermal hydrolysis pre-treatment: Effects of temperature and retention time. Environ. Res., 188 (2020), p. 109746

Kulikowska et al., 2020. D. Kulikowska, K. Bernat, I. Wojnowska-Baryła, B. Klik, S. Michałowska, S. Kasiński. Stabilizate from Autoclaved Municipal Solid Waste as a Source of Valuable Humic Substances in a Waste Circular Economy. Waste Biomass Valorization, 11 (11) (2020), pp. 6147-6157

Li et al., 2009. H. Li, Y. Jin, Y. Nie. Application of alkaline treatment for sludge decrement and humic acid recovery. Bioresour. Technol., 100 (24) (2009), pp. 6278-6283

Li et al., 2014. H. Li, Y. Li, S. Zou, C. Li. Extracting humic acids from digested sludge by alkaline treatment and ultrafiltration. J. Mater. Cycles Waste Manag., 16 (1) (2014), pp. 93-100.

Li et al., 2017. C. Li, X. Wang, G. Zhang, G. Yu, J. Lin, Y. Wang. Hydrothermal and alkaline hydrothermal pretreatments plus anaerobic digestion of sewage sludge for dewatering and biogas production: Benchscale research and pilot-scale verification. Water Res., 117 (2017), pp. 49-57

Liu et al., 2019. X. Liu, M. Zhang, Z. Li, C. Zhang, C. Wan, Y. Zhang, D.J. Lee. Inhibition of urease activity by humic acid extracted from sludge fermentation liquid. Bioresour. Technol., 290 (2019), p. 121767

Lu et al., 2020. D. Lu, D. Wu, T. Qian, J. Jiang, S. Cao, Y. Zhou. Liquid and solids separation for target resource recovery from thermal hydrolyzed sludge. Water Res., 171 (2020), p. 115476

Marin-Batista et al., 2020. J.D. Marin-Batista, A.F. Mohedano, J.J. Rodríguez, M.A. de la Rubia. Energy and phosphorous recovery through hydrothermal carbonization of digested sewage sludge. Waste Manag., 105 (2020), pp. 566-574

Mazaheri et al., 2010. H. Mazaheri, K.T. Lee, S. Bhatia, A.R. Mohamed. Subcritical water liquefaction of oil palm fruit press fiber in the presence of sodium hydroxide: an optimisation study using response surface methodology. Bioresour Technol., 101 (23) (2010), pp. 9335-9341

Nasir et al., 2011. S. Nasir, T.B. Sarfaraz, T.V. Verheyen, A.L. Chaffee. Structural elucidation of humic acids extracted from Pakistani lignite using spectroscopic and thermal degradative techniques. Fuel Process. Technol., 92 (5) (2011), pp. 983-991

Neyens and Baeyens, 2003a. E. Neyens, J. Baeyens. A review of classic Fenton's peroxidation as an advanced oxidation technique. J. Hazard. Mater., 98 (2003), pp. 33-50

Neyens and Baeyens, 2003b. E. Neyens, J. Baeyens. A review of thermal sludge pre-treatment processes to improve dewaterability. J. Hazard. Mater., 98 (2003), pp. 51-67 
Novak et al., 2001. J. Novak, J. Kozler, P. Janos, J. Cezikova, V. Tokarova, L. Madronova. Humic acids from coals of the North-Bohemian coal field I. Preparation and characterization.React. Funct. Polym., 47 (2001), pp. 101-109

Ooi et al., 2018. T.Y. Ooi, E.Y. Yong, M.F.M. Din, S. Rezania, E. Aminudin, S. Chelliapan, A. Abdul Rahman, J. Park. Optimization of aluminium recovery from water treatment sludge using Response Surface Methodology. J. Environ. Manage., 228 (2018), PP. 13-19

Quist-Jensen et al., 2018. C.A. Quist-Jensen, L. Wybrandt, H. Lokkegaard, S.B. Antonsen, H.C. Jensen, A.H. Nielsen, M.L Christensen. Acidification and recovery of phosphorus from digested and non-digested sludge. Water Res., 146 (2018), pp. 307-317

Sarlaki et al., 2019. E. Sarlaki, A. Sharif Paghaleh, M.H. Kianmehr, K. Asefpour Vakilian. Extraction and purification of humic acids from lignite wastes using alkaline treatment and membrane ultrafiltration. J. Clean. Prod., 235 (2019), pp. 712-723

Schnell et al., 2020. M. Schnell, T. Horst, P. Quicker. Thermal treatment of sewage sludge in Germany: A review. J. Environ. Manage., 263 (2020), p. 110367

Uma Maheswar Rao and Satyanarayana, 2007. J.L. Uma Maheswar Rao, T. Satyanarayana. Improving production of hyperthermostable and high maltose-forming a-amylase by an extreme thermophile Geobacillus thermoleovorans using response surface methodology and its applications. Bioresour. Technol., 98 (2) (2007), pp. 345-352

Wang et al., 2017. L. Wang, A. Li, Y. Chang. Relationship between enhanced dewaterability and structural properties of hydrothermal sludge after hydrothermal treatment of excess sludge. Water Res., 112 (2017), pp. 72-82

Wang et al., 2019. L. Wang, Y. Chang, A. Li. Hydrothermal carbonization for energy-efficient processing of sewage sludge: A review. Renew. Sust. Energ. Rev., 108 (2019), pp. 423-440

Wu et al., 2020. B. Wu, X. Dai, X. Chai. Critical review on dewatering of sewage sludge: Influential mechanism, conditioning technologies and implications to sludge re-utilizations. Water Res., 180 (2020), p. 115912

Yang et al., 2011. S. Yang, W. Guo, X. Zhou, Z. Meng, B. Liu, N. Ren. Optimization of operating parameters for sludge process reduction under alternating aerobic/oxygen-limited conditions by response surface methodology. Bioresour. Technol., 102 (21) (2011), pp. 9843-9851

Zhang et al., 2018. J. Zhang, N. Li, X. Dai, W. Tao, I.R. Jenkinson, Z. Li. Enhanced dewaterability of sludge during anaerobic digestion with thermal hydrolysis pretreatment: New insights through structure evolution. Water Res., 131 (2018), pp. 177-185 
Zhang et al., 2019. Y. Zhang, S. Xu, M. Cui, J. W. C. Wong. Effects of different thermal pretreatments on the biodegradability and bioaccessibility of sewage sludge. Waste Manag., 94 (2019), pp. 68-76

Zhao et al., 2016. H. Zhao, P. Zhang, G. Zhang, R. Cheng. Enhancement of ultrasonic disintegration of sewage sludge by aeration. J. Environ. Sci. (China), 42 (2016), pp.163-167

Zhou et al., 2018. H. Zhou, H. Meng, L. Zhao, Y. Shen, Y. Hou, H. Cheng, L. Song. Effect of biochar and humic acid on the copper, lead, and cadmium passivation during composting. Bioresour. Technol., 258 (2018), pp. 279-286

\section{Declarations}

\section{Ethics approval and consent to participate}

Not applicable

\section{Consent for publication}

Not applicable

\section{Availability of data and materials}

All data generated or analyzed during this study are included in this published article (and its supplementary information files).

\section{Competing interests}

The authors declare that they have no known competing financial interests or personal relationships that could have appeared to influence the work reported in this paper.

\section{Funding}

This work was supported by the National Natural Science Foundation of China (Grant No. U1901216), the Guangdong Science and Technology Program (2020B121201003) and the Guangdong Innovative and Entrepreneurial Research Team Program (No. 2016ZT06N569).

\section{Authors' contributions}

Chen Qiu: Conceptualization, Investigation, Data curation, Writing- original draft, Writing-review \& editing, Visualization.

Wenbing Xu: Resources, Writing - review \& editing.

Yanjie Wang: Writing - review \& editing, Visualization. 
Xintai Su: Conceptualization, Investigation, Methodology, Project administration, Writing-review \& editing, Supervision, Funding acquisition.

Zhang Lin: Writing-review \& editing, Funding acquisition.

\section{Acknowledgments}

The author would like to acknowledge Prof. X.T., Su for his continuous help and support. The authors acknowledge the research and testing platforms provided by the South China University of Technology and Sino-Singapore International Joint Research Institute.

\section{Tables}

Table 1 The main characteristics of RS sample

\begin{tabular}{cccc}
\hline Water content (\%) & $\mathrm{pH}$ & Organic matter (\%) & Total HA (\%) \\
\hline 78.6 & $6.02-6.16$ & 30.3 & 6.72 \\
\hline
\end{tabular}

Table 2 Independent variables, their domain, and experimental data for Box-Behnken design 


\begin{tabular}{|c|c|c|c|c|c|}
\hline \multirow[t]{2}{*}{ Independent variable } & \multirow[t]{2}{*}{ Factor code } & \multicolumn{4}{|c|}{ Level of factors } \\
\hline & & \multicolumn{2}{|c|}{-1 Level } & 0 Level & +1 Level \\
\hline Hydrothermal temperature $\left({ }^{\circ} \mathrm{C}\right)$ & $\mathrm{X}_{1}$ & \multicolumn{2}{|c|}{170} & 180 & 190 \\
\hline Hydrothermal time (min) & $\mathrm{X}_{2}$ & \multicolumn{2}{|c|}{30} & 60 & 90 \\
\hline The ratio of alkali to sludge & $\mathrm{X}_{3}$ & \multicolumn{2}{|c|}{0.01} & 0.025 & 0.04 \\
\hline \multirow[t]{2}{*}{ Run } & \multicolumn{3}{|c|}{ Code levels } & \multirow{2}{*}{$\begin{array}{l}\text { HA extraction } \\
\text { rate (\%) }\end{array}$} & \multirow[t]{2}{*}{ Water content (\%) } \\
\hline & $\mathrm{X}_{1}$ & $\mathrm{X}_{2}$ & X3 & & \\
\hline 1 & 1 & 0 & 1 & 60.98 & 51.7 \\
\hline 2 & 1 & 0 & -1 & 50 & 67.22 \\
\hline 3 & 1 & 1 & 0 & 60.38 & 55.34 \\
\hline 4 & 0 & 1 & -1 & 37.45 & 52.54 \\
\hline 5 & 0 & 0 & 0 & 72.1 & 56.38 \\
\hline 6 & 0 & 0 & 0 & 70.1 & 51.9 \\
\hline 7 & 0 & 1 & 1 & 63.74 & 43.7 \\
\hline 8 & 0 & 0 & 0 & 73.1 & 53.55 \\
\hline 9 & 0 & 0 & 0 & 76.8 & 53.12 \\
\hline 10 & -1 & 1 & 0 & 71.2 & 53.93 \\
\hline 11 & -1 & 0 & -1 & 38 & 69.63 \\
\hline 12 & -1 & 0 & 1 & 91.03 & 50.76 \\
\hline 13 & 0 & 0 & 0 & 75.9 & 52.64 \\
\hline 14 & -1 & -1 & 0 & 87.74 & 72.69 \\
\hline 15 & 0 & -1 & -1 & 49.21 & 75.12 \\
\hline 16 & 0 & -1 & 1 & 88.62 & 54.54 \\
\hline 17 & 1 & -1 & 0 & 75.8 & 70.87 \\
\hline
\end{tabular}

Table 3 Mass fraction of heavy metals in the purified HA in the study and its comparison with the values in National Standard GB/T 23349-2009 


\begin{tabular}{cccccc}
\hline Element & $\mathrm{As}$ & $\mathrm{Cd}$ & $\mathrm{Cr}$ & $\mathrm{Pb}$ & $\mathrm{Hg}$ \\
\hline HA & 0.0010 & 0.0001 & 0.015 & 0.0006 & 0.0002 \\
National Standard & $\leq 0.0050$ & $\leq 0.0010$ & $\leq 0.0500$ & $\leq 0.0200$ & $\leq 0.0005$ \\
\hline
\end{tabular}

Table 4 Relative molecular mass of product

\begin{tabular}{cccc}
\hline Distribution Name & $\mathrm{M}_{\mathrm{n}}$ & $\mathrm{M}_{\mathrm{w}}$ & Polydispersity \\
\hline molecular mass & 20602 & 43015 & 2.0879 \\
\hline
\end{tabular}

\section{Figures}
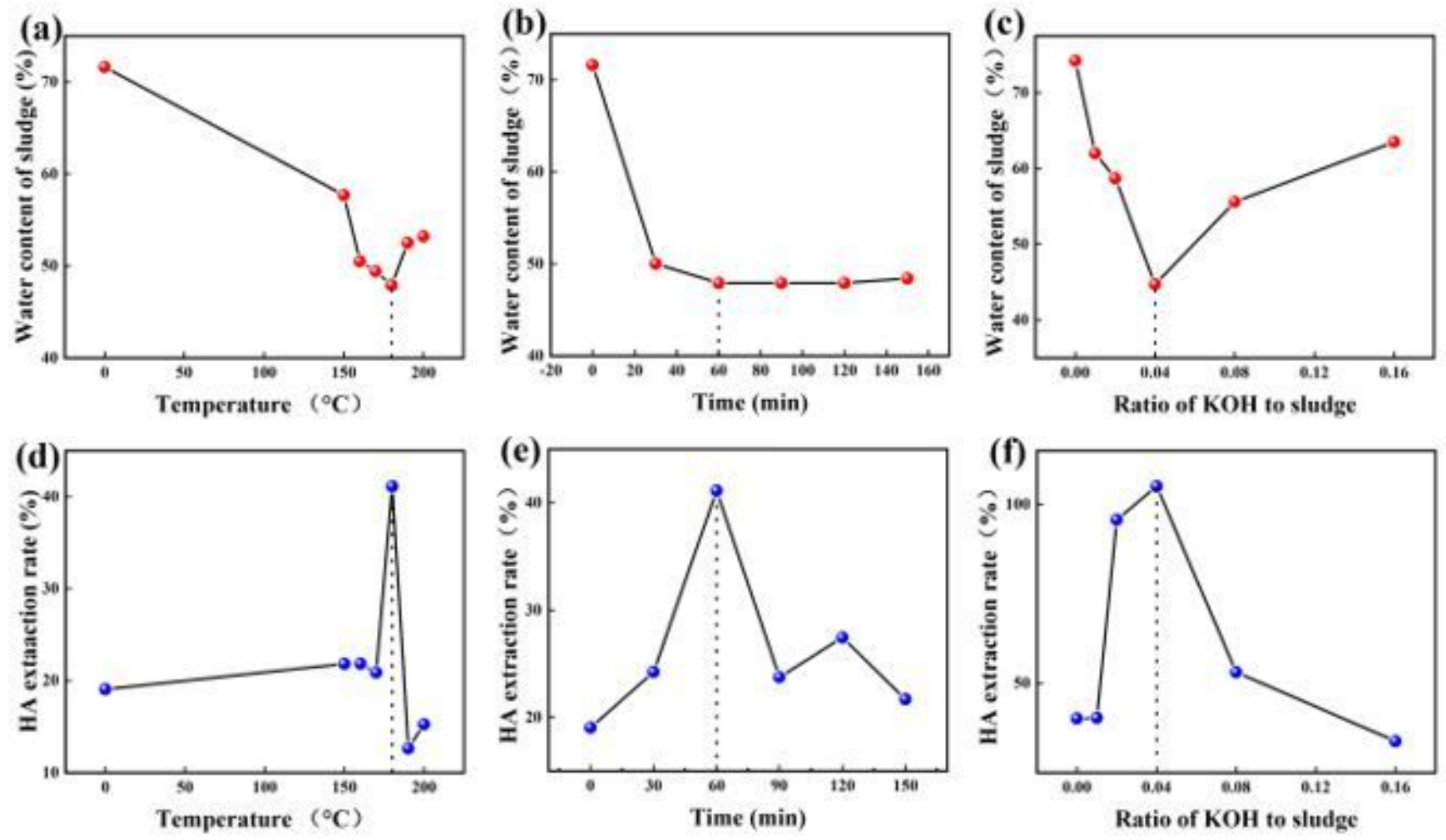

Figure 1

Effects of (a) thermal hydrolysis temperature, (b) hydrothermal time, (c) ratio of $\mathrm{KOH}$ to sludge on water content, (d) hydrothermal hydrolysis temperature, (e) hydrothermal time, (f) ratio of $\mathrm{KOH}$ to sludge on $\mathrm{HA}$ extraction rate of sludge. 

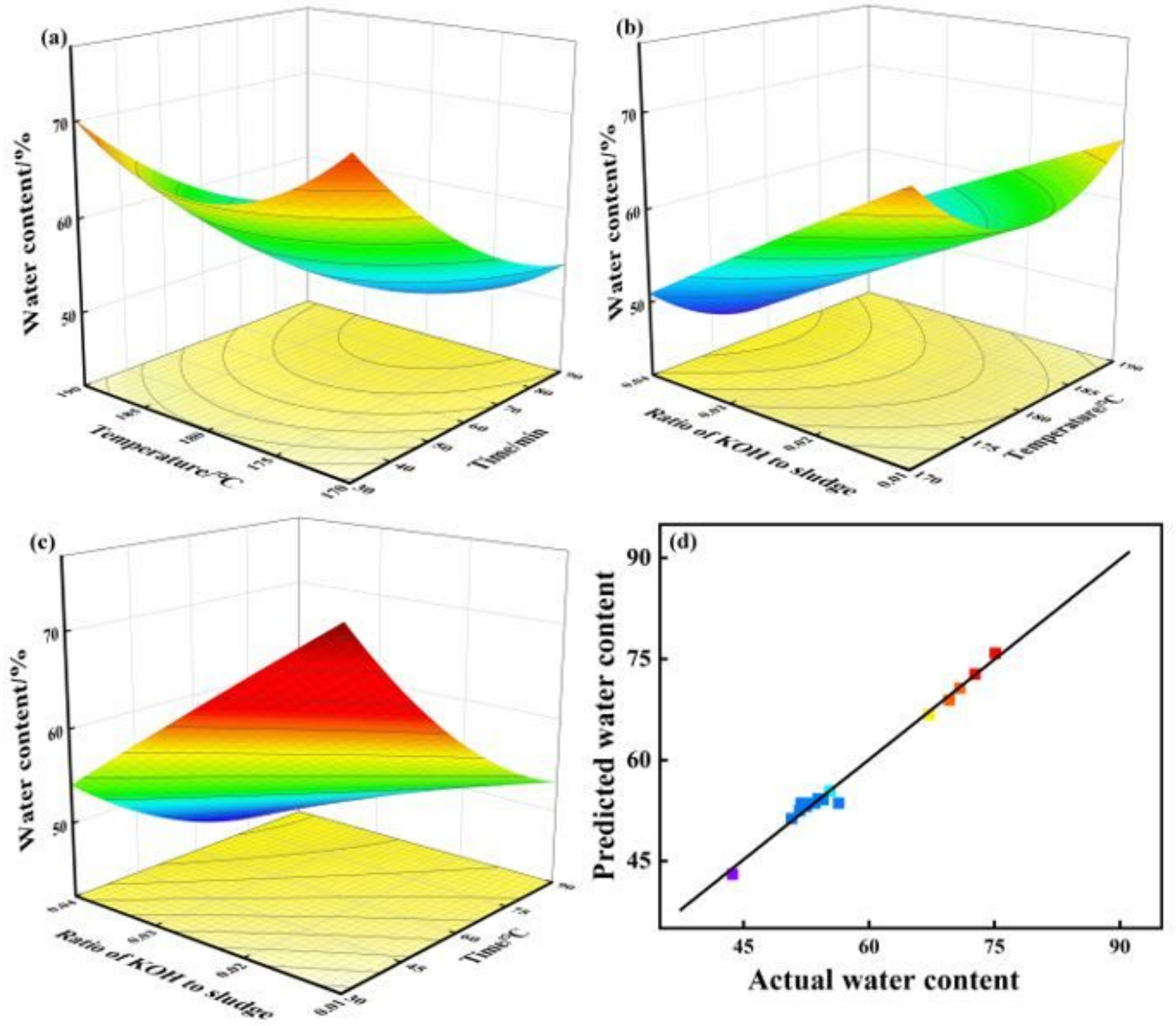

Figure 2

3D response surface and contour plots showing the effect of (a) hydrothermal temperature and hydrothermal time, (b) hydrothermal temperature and the ratio of $\mathrm{KOH}$ to sludge, (c) hydrothermal time and the ratio of $\mathrm{KOH}$ to sludge on the change of sludge water content, (d) comparison between the predicted value of the model and the variation of sludge water content during the experiment. 

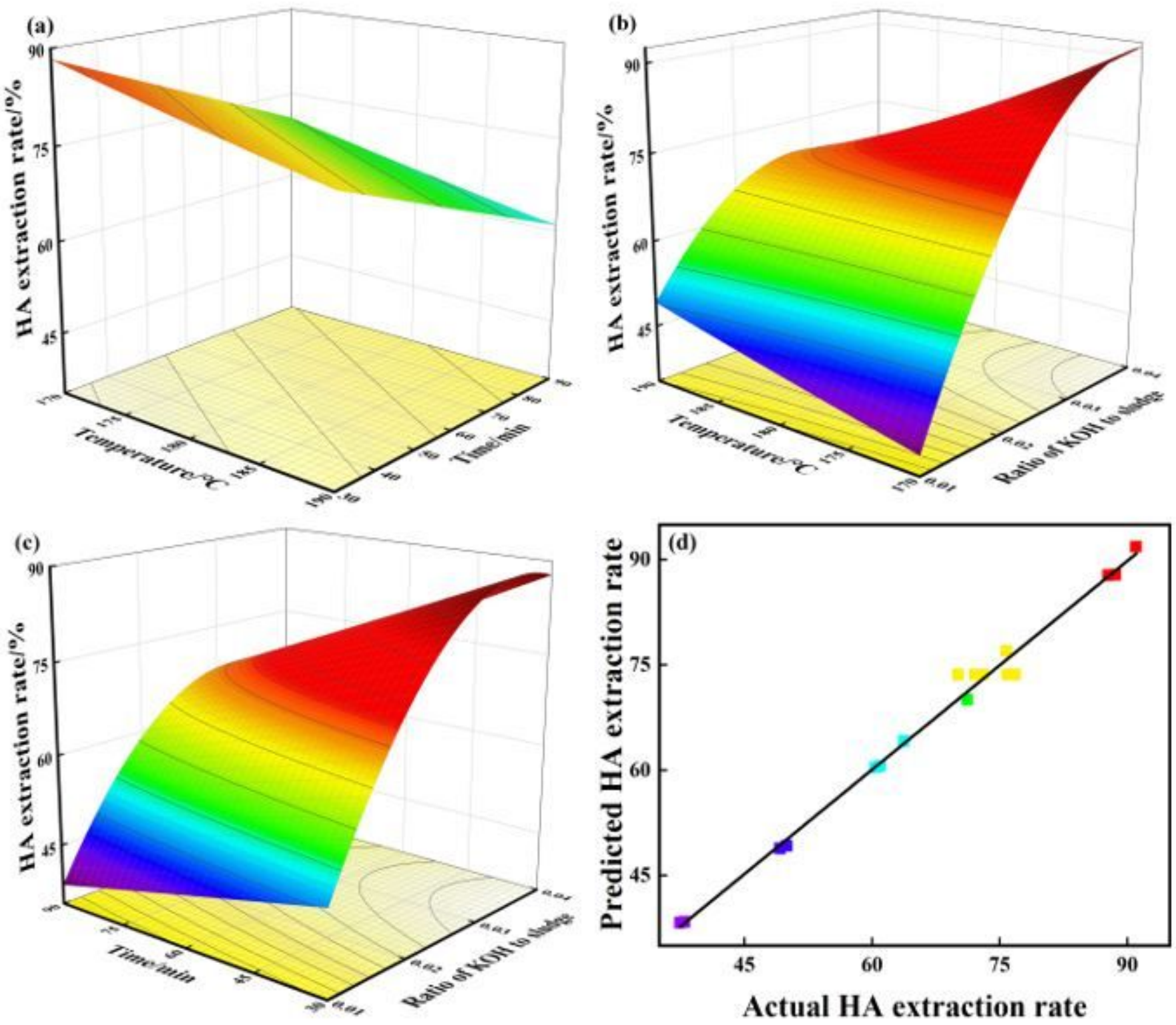

\section{Figure 3}

$3 \mathrm{D}$ response surface and contour plots showing the effect of (a) hydrothermal temperature and hydrothermal time, (b) hydrothermal temperature and the ratio of $\mathrm{KOH}$ to sludge, (c) hydrothermal time and the ratio of $\mathrm{KOH}$ to sludge on the $\mathrm{HA}$ extraction rate, (d) Comparison between the predicted value of the model and the variation of HA extraction rate during the experiment. 


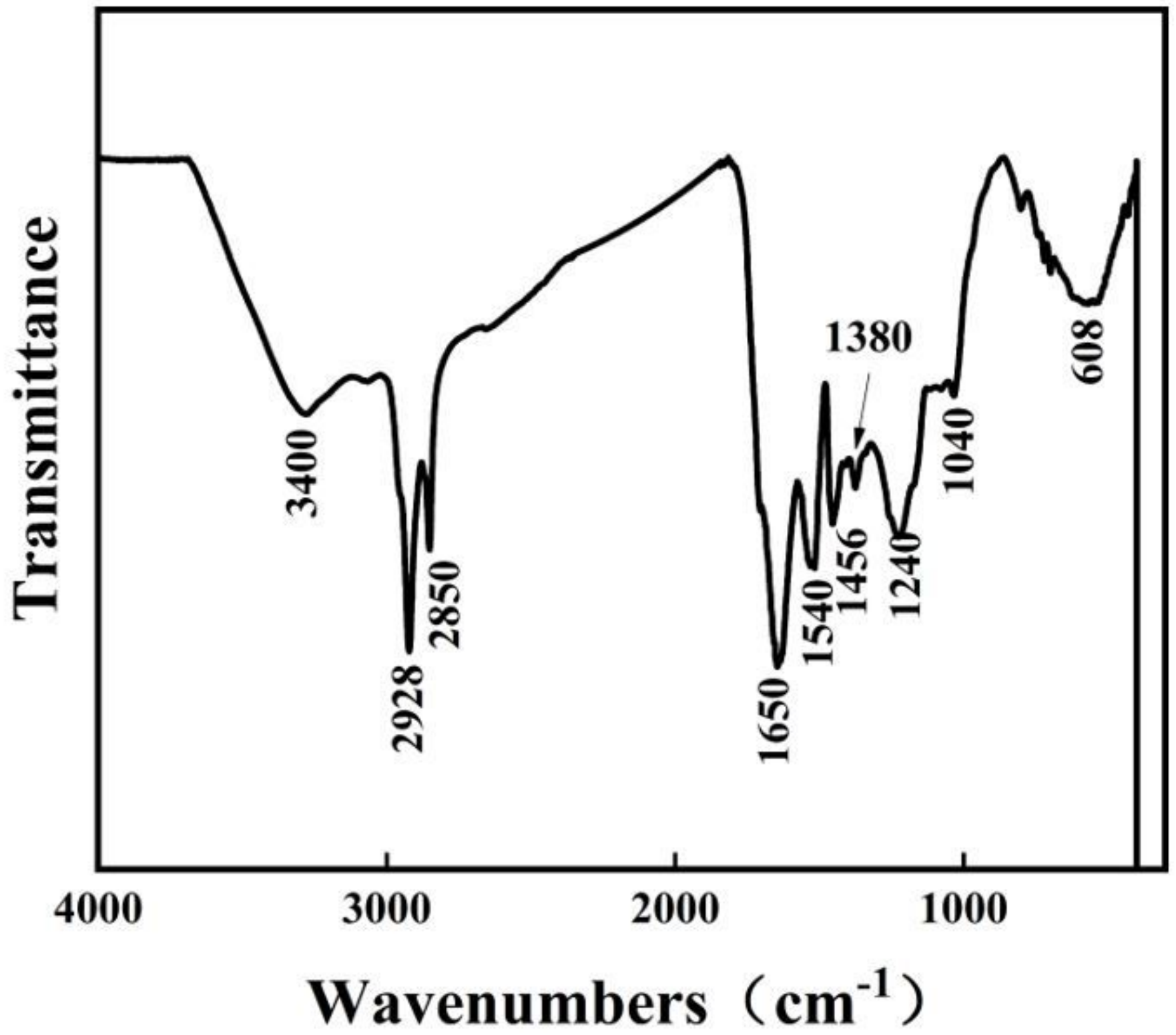

Figure 4

Infrared spectrogram of HA 

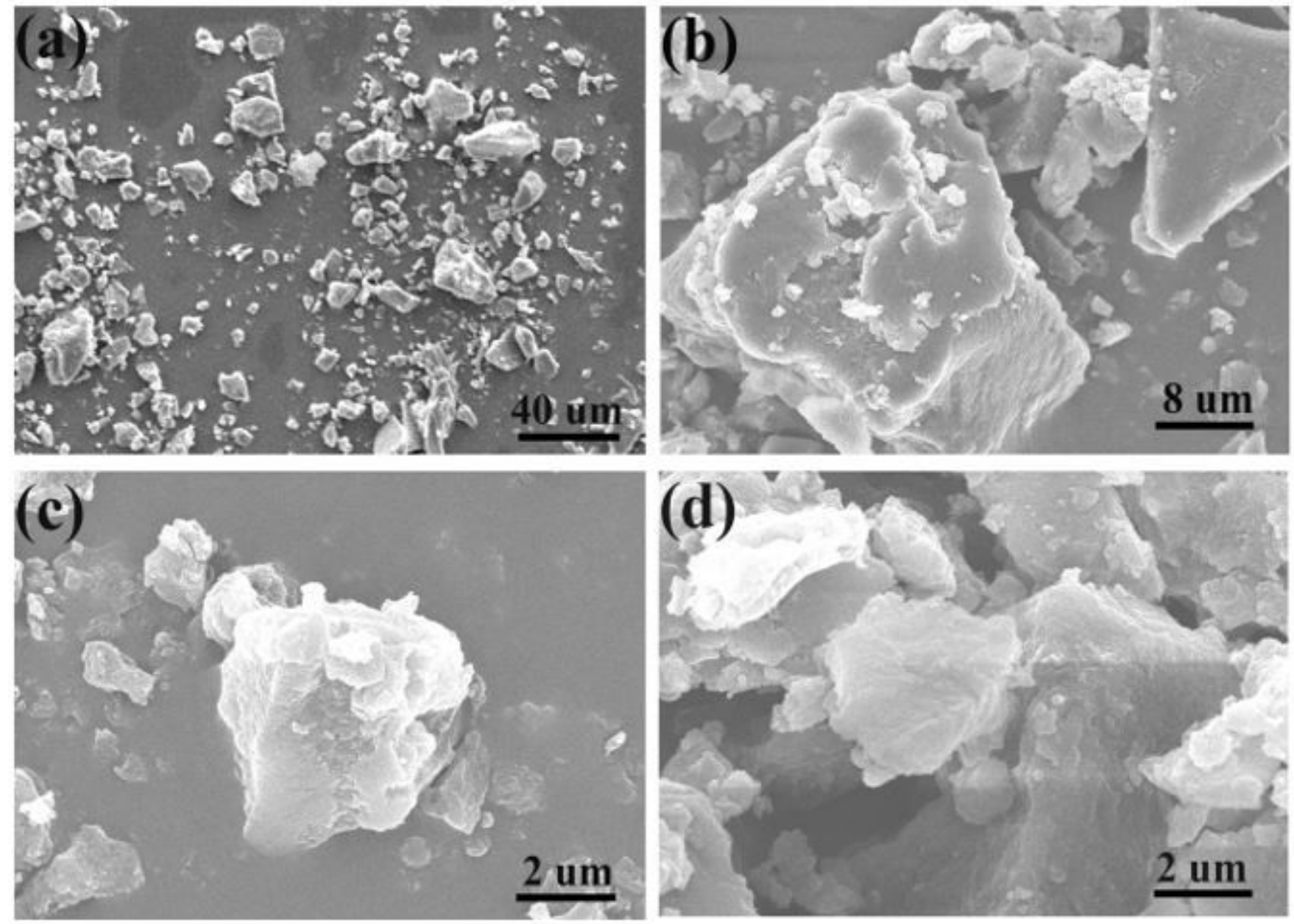

\section{Figure 5}

SEM images of (a) HA of 500 times, (b) HA of 2500 times, (c) HA of 10000 times, (d) HA of 10000 times. 


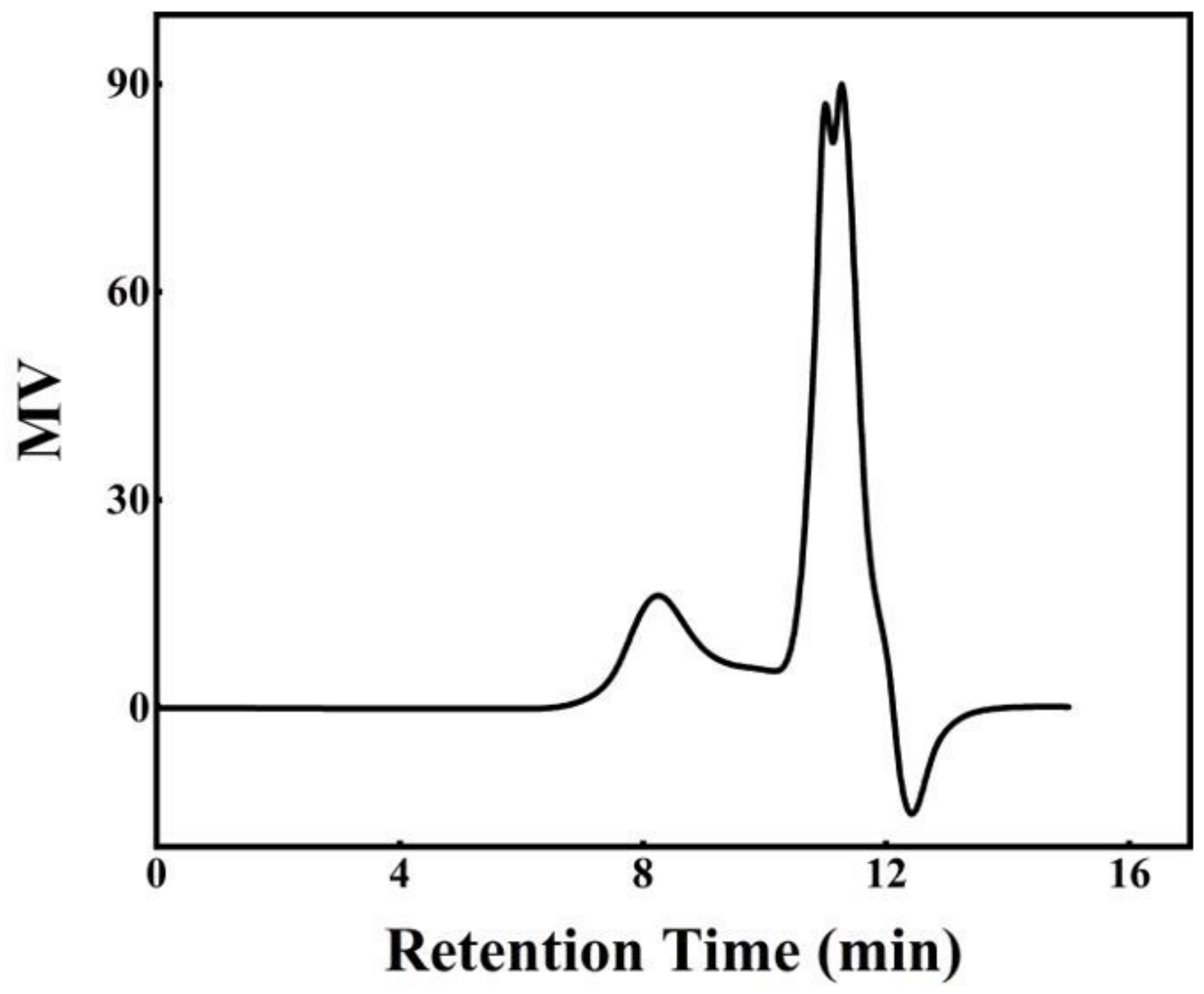

Figure 6

Relative molecular mass and its distribution of $\mathrm{HA}$

Supplementary Files

This is a list of supplementary files associated with this preprint. Click to download.

- SupplementaryInformation.docx 